\title{
A FINANCIAL SIMULATION MODELING FOR MAJOR UNIVERSITY IN THE MIDDLE EAST
}

\author{
Ahmed A. Bakhsh \\ Industrial Engineering Department, Faculty of Engineering, \\ King Abdulaziz University Jeddah, 21589, Saudi Arabia \\ E-Mail:aabakhsh@kau.edu.sa
}

\begin{abstract}
In the present economic environment, it is critical for organizations to precisely monitor and forecast financial issues for better decision-making. This study constructed a model for the college of Engineering's financial operation of a major University in the Middle East by looking at the numbers of its revenues and expenses. Moreover, object-oriented simulation (OOS) tools is used for the financial model that support the subject matter experts in how the model can be used to help them make decisions regarding topics such as: does it make sense to introduce a new major now or in the future, should the college try to enroll more students, or even should a specific course be offered at a specific semester. The simulation model helps in financial terms only. The OOS helps in dealing with complexity because of the enhanced modularity that can be applied and the implied use of abstraction to mimic the way the finances of the university work. The study results show the optimum number of courses to be taught based on the availability of instructors in each track is identified. Also, it shows that four courses with more than 60 students and need a GTA to be hired.
\end{abstract}

Keywords: Financial Model; OOS; University; Engineering

\section{INTRODUCTION}

The simulation is powerful tool that help in decision - making process and evaluate decisions before implementation (Toklu \& Şimşek, 2018). It's been used widely to support decisions for instance a financial feasibility study (Mardiansyah, Kusrini, \& RM, 2018). The main goal for this study is to create a financial simulation model of academic productivity that includes a detailed analysis of revenues and costs for operating the College of Engineering for a major University in the Middle East. The analysis on how the University's College of Engineering gains its revenues as well as how much it cost the college to operate are considered.

The problem is to find out optimal number of teaching courses in a semester based on students enrolling at the college of engineering in terms of minimal direct and indirect costs associated to the total operation cost of the college.
The objectives for this study are to help understand a detailed analysis of revenues and costs for operating the University's College of Engineering visually; to find out the breakeven point of a course being offered, for a program, department or college; and an Object-oriented Simulation (OOS) approach to enable an extendable system for different behaviors that introduced to test new hypotheses.

On the other hand, the measures of performance concerned college's departments per academic semester; are as follow:

- Number of students in each of the College's departments per course per semester.

- Number of courses offered in each of the College's departments per course per semester.

- Direct revenues: tuition, special fees (lab fees and other). 
- Direct expenses: instructor's salary which is $25 \%$ for fulltime, pay check for student assistants and lab supplies in each of the College's departments per course.

- Expected expenses in each of the College's departments per course.

The rest of this paper is ordered as follows. The following section presents the methodology. The results and discussion are described in Section 3. The conclusion is presented in Section 4. Suggestions are given in section 5 .

\subsection{The Financial Practice}

The finance is vital to organizations and full awareness to financial management is the key of success. It is a source of advantage that lead the organization for competitive advantage. Thus, the financial modelling represents the performance of financial assets in every aspects of business and is crucial to decision making inside and outside the organization (Strang, 2012). For instance, the financial modeling assessed the energy projects and shown the importance to renewables than for fossil fuel-based power plants (Steffen, 2018).

Many studies have built simulation models to decision-makers for financial analysis and proven powerful consequences such as the simulation model built for the suppliers of funding to the financial institutions that use funds to trade in asset markets (Bookstaber, Paddrik, \& Tivnan, 2018).

The simulation modelling also built for financial risk for highway infrastructure projects (Kumar, Jindal, \& Velaga, 2018). Next, Simulation modelling is used for action in college admissions and study the relations between students and their college that addressed concerns for decision-makers (Reardon, Baker, Kasman, Klasik, \& Townsend, 2018).
Moreover, a study simulate graduate loan schemes and relation to higher education financing (Chapman \& Doris, 2018). However, the financial simulation model in academic is the major concerned for this paper.

\section{METHODOLOGY}

The University's College of Engineering financial model is built, using objectoriented simulation software that tries to mimic the way the finances of the university work (Figure 1 shows the flow of money from the government support to the department of Industrial Engineering, IE). The data to run the simulation model is obtained for Fall 2018 from Industrial Engineering Department of a major University in the Middle East. The following are the simulation model assumptions and scenarios:

1. Students come and selects courses available based on their track.

2. At registration time, system checks student eligibility, such as pre-requisites and if seats are available.

3. Immediately after registration closes, the college checks whether the class will be taught in one or more sections or if it will be cancelled.

For the validation, the results from simulation model are compared to actual numbers and showed accuracy. 


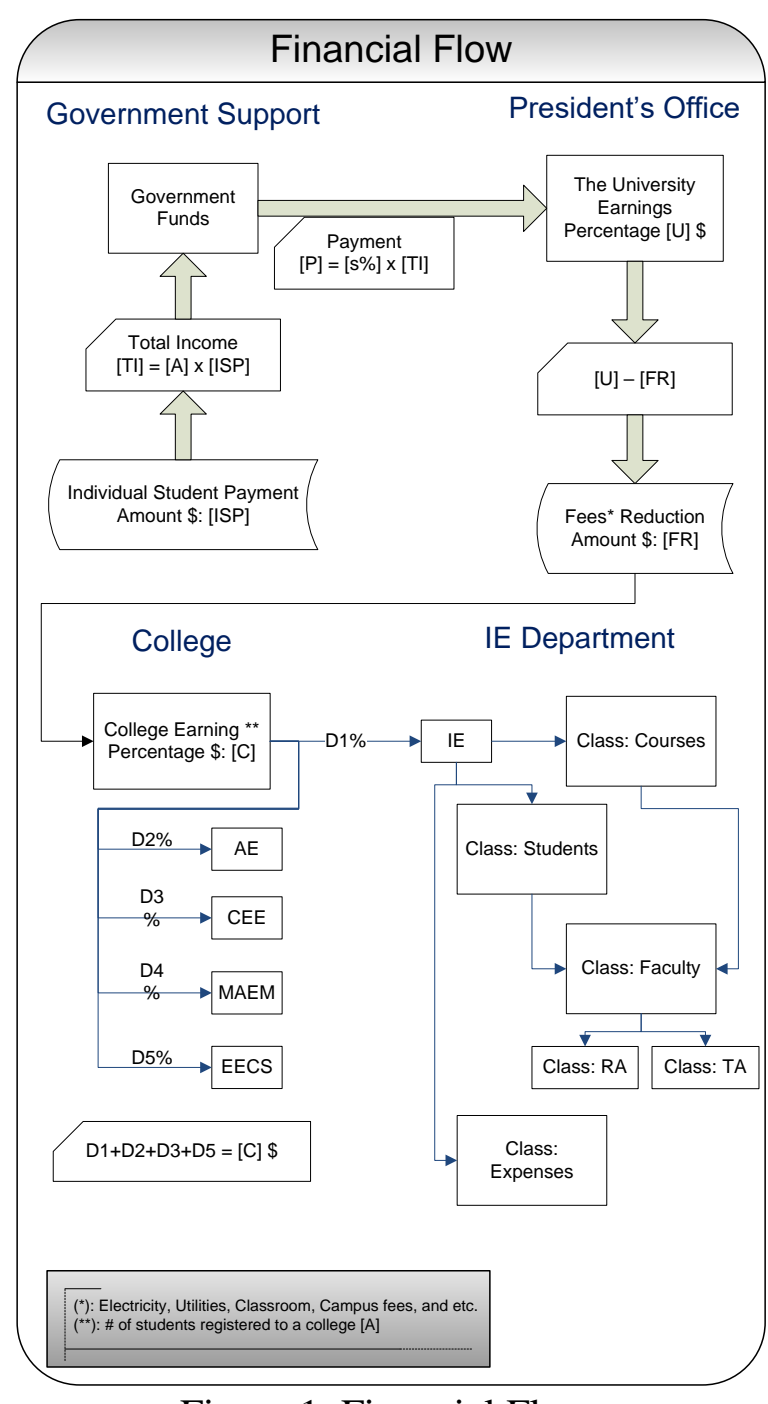

Figure 1. Financial Flow

\section{a. Revenues}

The University has many sources of funding, including tuition from students, the government funds, grants, rents (from stores inside the University), royalties (food stands, the University memorabilia - clothes and others using the logo), etc. It has been figured out by talking to different people in the University specially to the people there in College of Engineering Administration office, the finances are very confusing, with no one having a full understanding of them. Based on this understanding, it been assumed that money of the University comes from the government support, student tuition, royalties, funds, grants, etc. (Folsom, 2019). The money is a function of the number of students enrolled.

\section{b. Expenses}

The University allocates part of the money to the different colleges, with the remaining being used to pay for cleaning, gardening, maintenance, the student union, police, etc. Each college in turn allocate part of the money they receive to its different departments. The remaining part of the money is used to pay for equipment maintenance, new equipment, materials, travel, training, etc. Katz and Kahn infer that when a system is a subsystem of a larger system, there must be multiple goals in the larger system. In the presence of multiple and competing goals, optimal allocation of resources is not easily determined (Gustafsson \& Jarvenpaa, 2018).

A main component of the college's cost is the number and rank of faculty in the payroll. However, the money each college gets is a function of the number and type (undergrad or grad) of students in that college. Likewise, the money each department gets is a function of the number and type of students in that department. Every department in the university has it detailed vision, objectives, goals, priorities, and programs (Elias \& Mehrotra, 2018). Specialized equipment, like FEEDS classrooms, is charged directly to the students in the form of FEEDS charges in the tuition. FEEDS are offered in both undergraduate and graduate courses, the undergraduate courses served online through the university platform.

Each department must pay out of its allocated money the salaries for all employees, including professors, staff, graduate teaching assistants (GTAs), etc., as well as some other expenses, like office supplies, telephone, and computer software. The cost of the salaries of the professors depends on the rank of the faculty in the payroll. As mentioned by the department accountant, the departments do not cover the cost of the classrooms, nor the electricity, parking spaces, etc. 
The rule of the college is that as long as the department can get an instructor (who is paid) inside the classroom for the time it's requested, the classroom is granted as mentioned by the college accountant.

A professor needs to teach four courses each semester. They can "buy" the right not to teach a course by getting projects (grants), serving in university positions (like faculty council, graduate or undergraduate coordinator, etc.). If the position is outside of the department, that position pay the ratio of the professor's salary instead of the department. Each professor also has a specialty, and the idea is that they teach in that specialty; in order to teach a subject, the instructor must be competent in that area.

\section{c. The financial flow}

Once the university gets its budget, it allocates an amount to each college. When the college gets its share, it allocates a percentage of it to each department based on the number of students in that department. A simulation is run depending on the number of students in the departments.

The departments (IE is used as an example) have a certain number of instructors. They can be full time professors, visiting professors, etc. Each instructor has a specialty they teach, and they lecture to both undergraduate and graduate students. By knowing the courses that are going to be taught in any given semester, and the specialty of the course, a linear programming model is made to figure out how many instructors are needed for each specialty. Management science models can help to achieve better planning in nonprofit institutions like universities just as they do in business and government (Johnes, 2015). More information is found in the Use Case Diagram.

UML software is used to capture the architecture of system, its sub-systems, relations, behavior, within the problem boundaries discussed above (Harmon \& Watson, 1998). Figure 2 displays the methodology that is used during the process. The interaction is captured between the actors, classes, use-cases and requirements by assigning relations within an entry. For example, the Manage Research Use Case have its own Activity, Use Case, Sequence, and State Chart diagram while at the same time is a part of a higher level's Use Case Diagram (Roques, 2006).

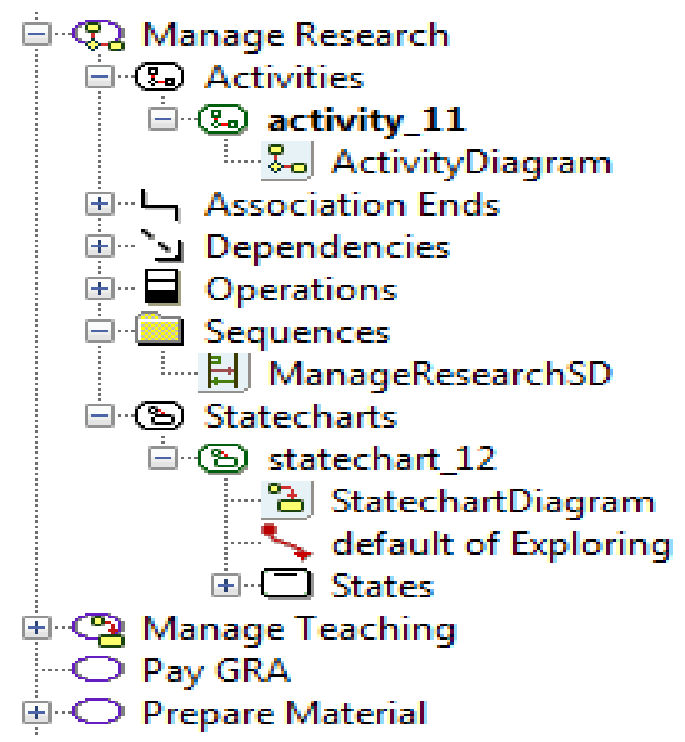

Figure 2. Design Methodology

\section{d. Major Classes}

Three main classes are considered in the model designed to support the system as Actor, Course and School that can be described in the major classes with inheritance. Each actor is then grouped into their subclasses.

\section{e. Class Number 1- Actor}

The following class represent the actors involved in the University Education System. The main Actor class has the attributes which are common for all the inherited classes, such as, ID and specialty. The Actor class is designed to inherit two classes, Faculty and Student each having specific attributes and operations. For instance, the Student class consists of three classes, Student graduate research assistant (GRA), Student graduate teaching assistant (GTA) and the Student Only. The "Student Only" name stands for the students who are not currently an employee of the University. The student class is designed as such in 
order to capture the expenses of the department, like GTA tuition, and salary.

\section{f. Class Number 2-Course}

The following class represent the University's courses offered by department. Moreover, objects are created for detail to each degree course. The attributes addressed in the Course class include specialty, GTA requirement, code which help to assign the relation between a course and the faculty, GTA, and department. The operations and attributes of the Course class are captured in the Class 2 "Course".

\section{g. Class Number 3- School}

The last main class represent the university's divisions called the School which inherits two classes Department and College. The Department and College are designed on the same level of inheritance rather than inheriting the Department from College due to the differentiation in their operations such as Pay Department Income.

\subsection{Classes Diagrams And Major Objects}

The diagram below shows the major classes with inheritance relationship (Figure 3). Every class is associated to a unique object. For example, Figure 4 shows the relevant objects of the Department class within the boundaries of the system design.

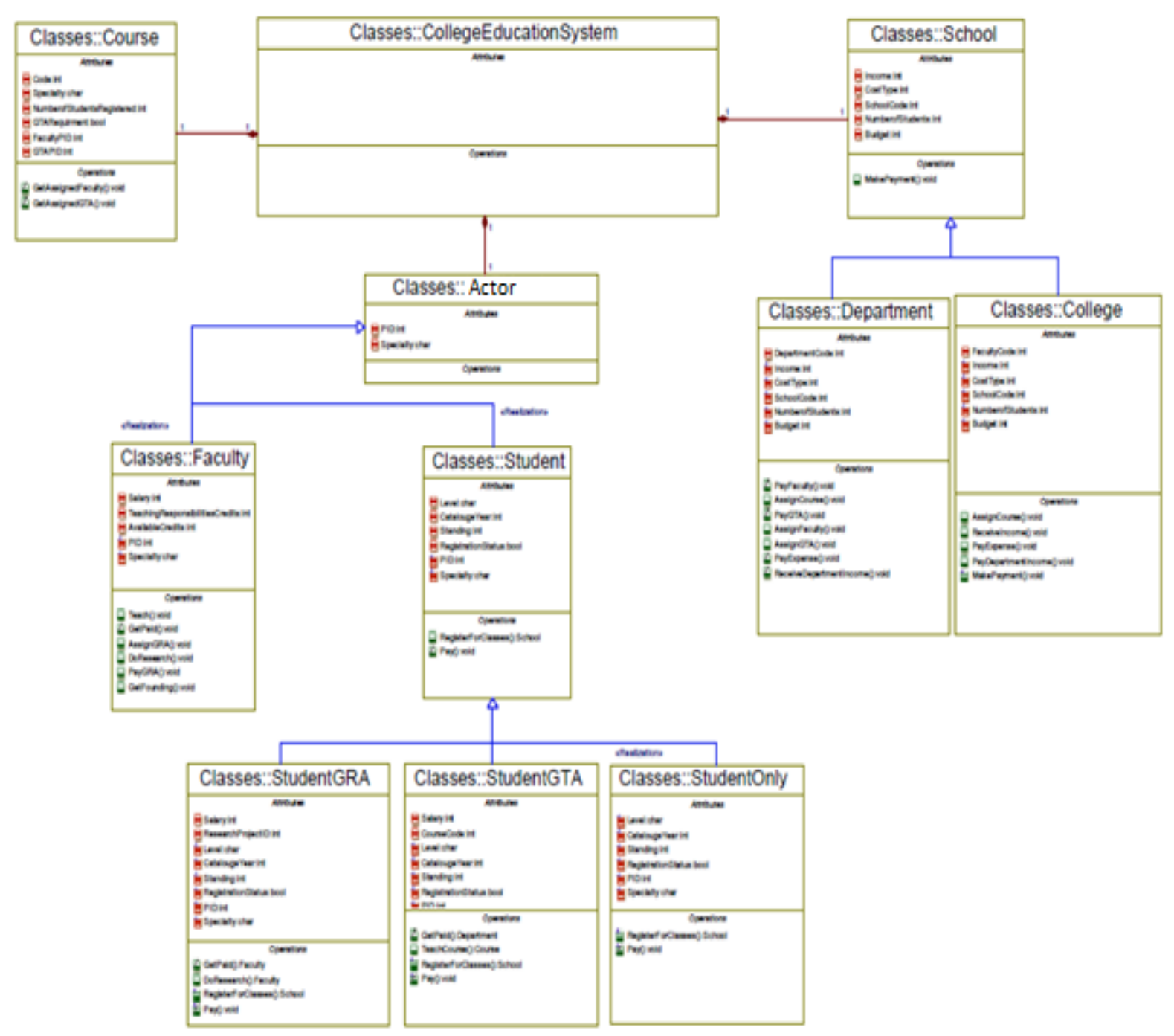

Figure 3. Major Classes with Inheritance Relationship 


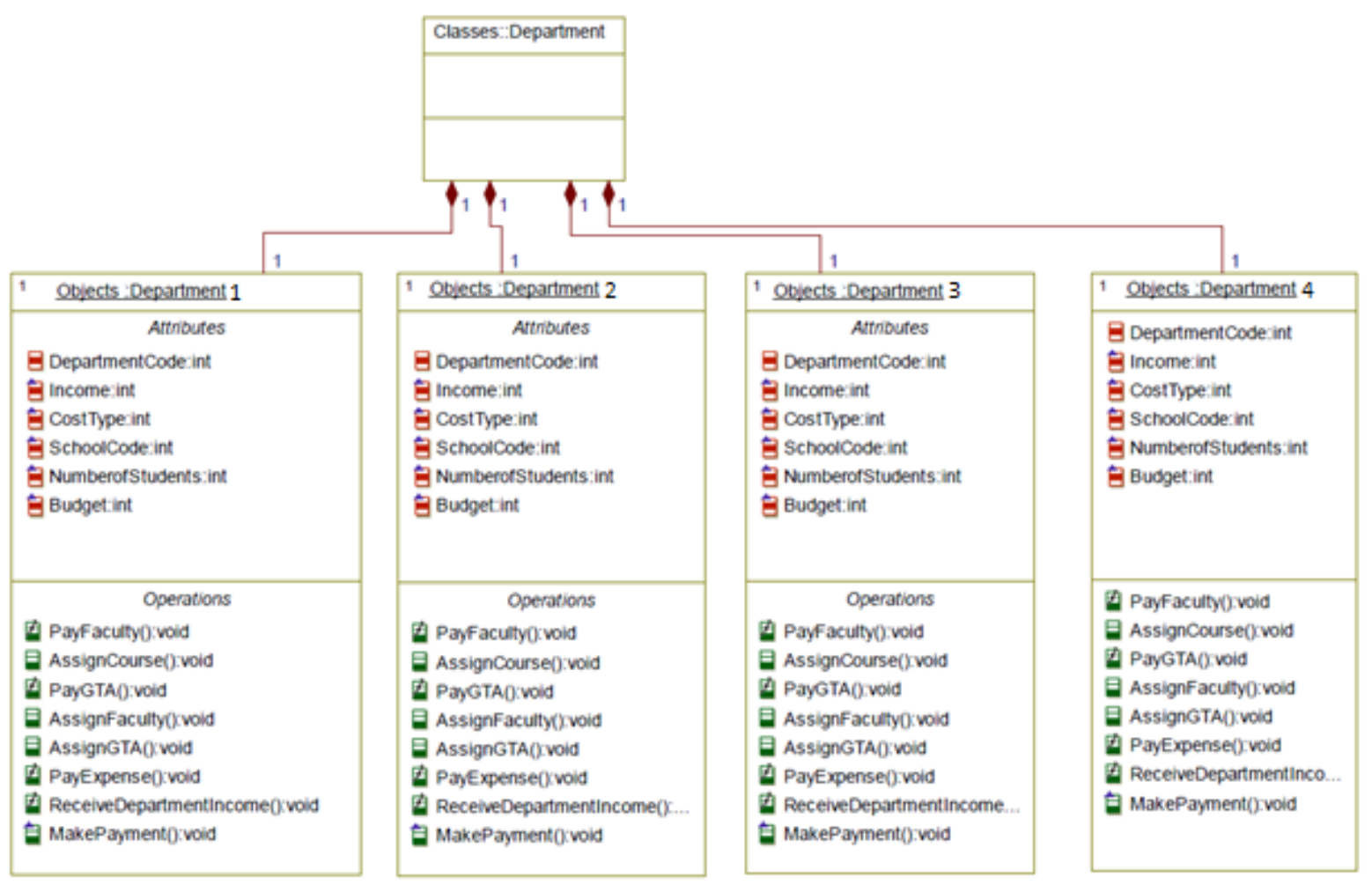

Figure 4. Major Objects

\subsection{Use Case Diagrams}

Use case diagrams represent a high-level view of the class faculty usage as viewed from the group members' perspective. These diagrams show the functionality of the class and how the model interacts with the outside world.
Use case diagrams are being used during analysis to capture the system or model requirements and to understand how the system should work. Figure 5 show the main use case diagrams of the class faculty. In addition, Figure 6 and Figure 7 show the detailed use case diagrams of the class faculty.

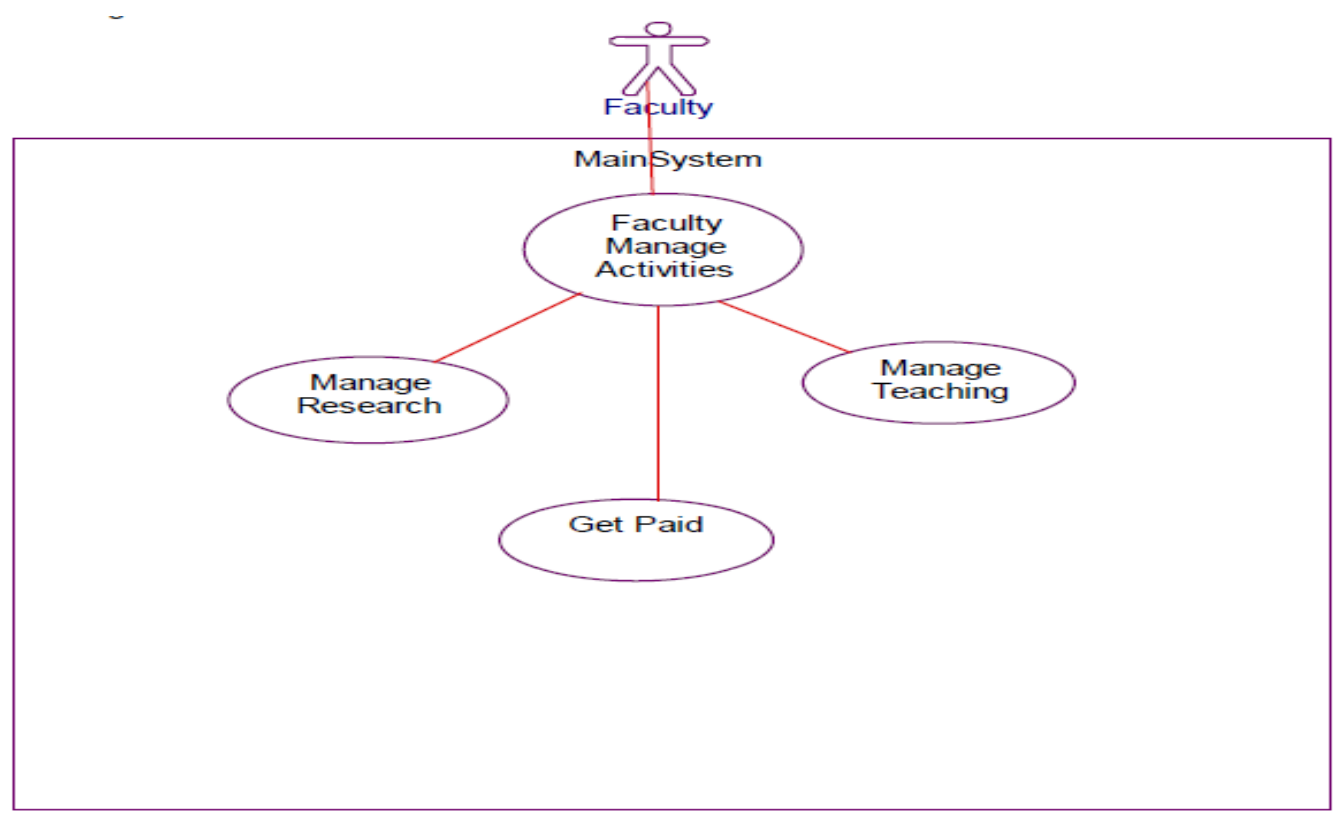

Figure 5. Main Use Case Diagrams of the Class Faculty 


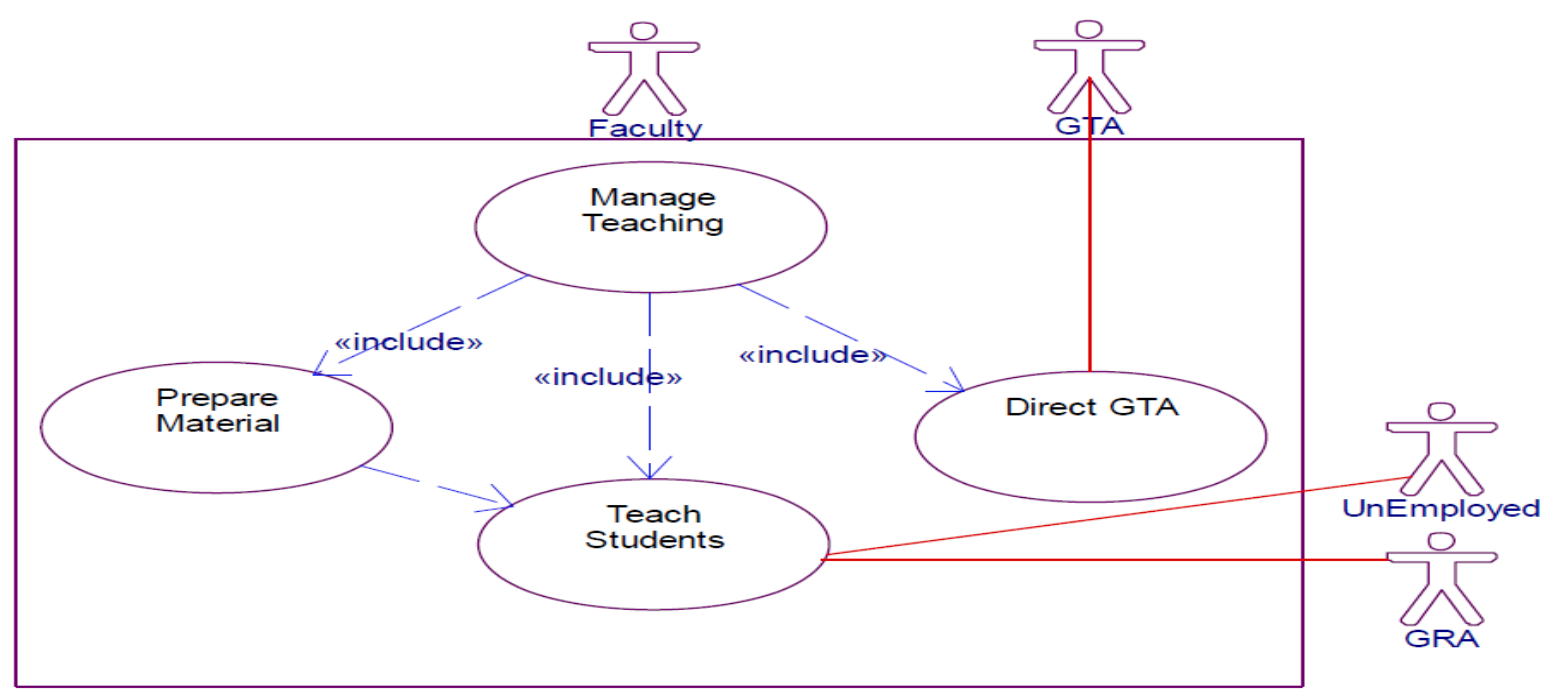

Figure 6. Use Case Diagrams of the Class Faculty - Manage Teaching

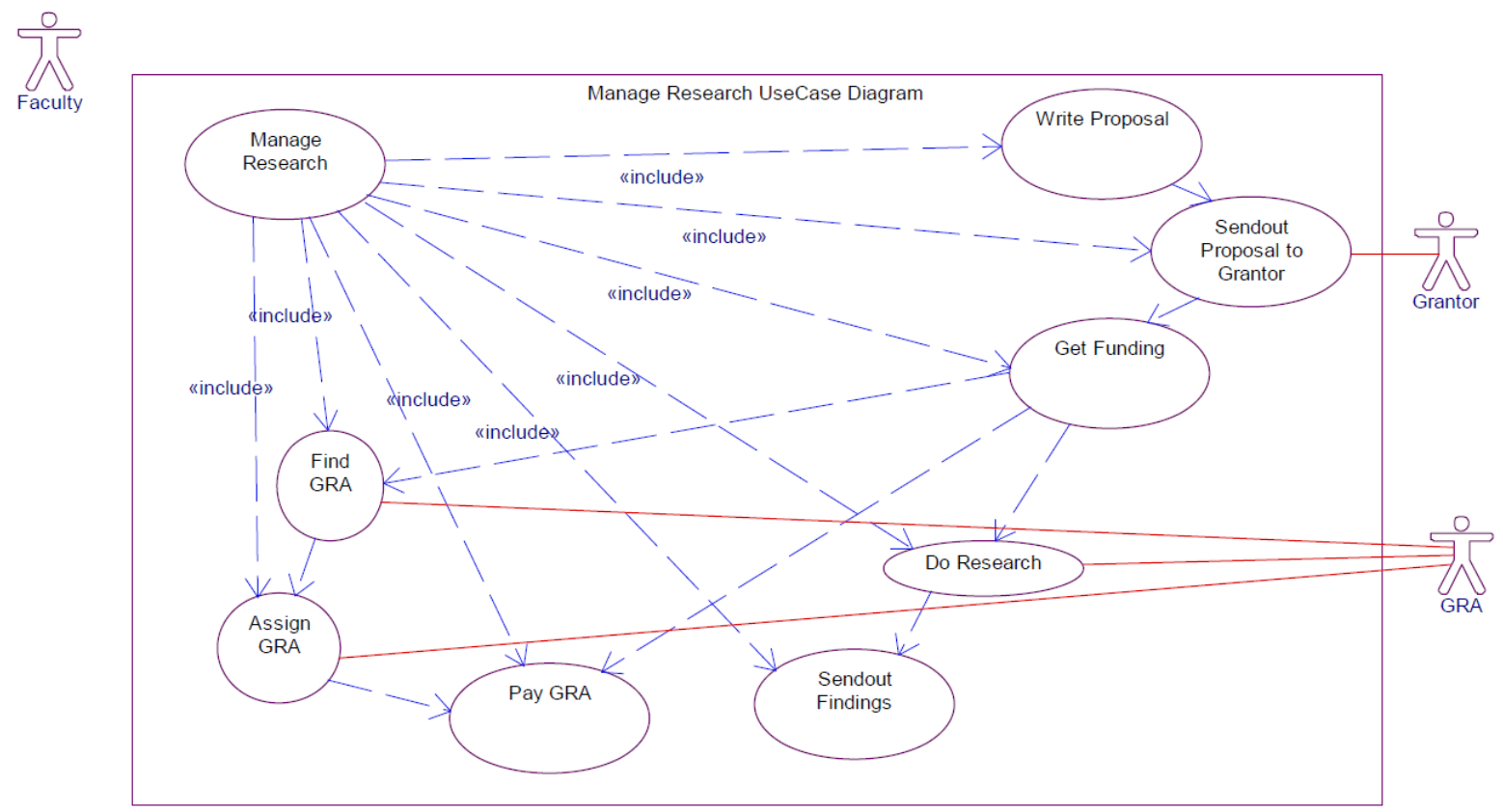

Figure 7. Use Case Diagrams of the Class Faculty - Manage Research

\section{RESULTS AND DISCUSSION}

The simulation model based on assumptions listed in the methodology section above is built for the semester of Fall 2018 to IE department which offered 24 courses in diverse tracks such as Industrial Engineering, Operation Research, and Engineering Management in graduate programs. The model also assumes all incoming graduate students are full time students who need to register three classes. Each student has their own priority courses choosing based on their own track. For example, if the student is from Engineering Management track then the highest priority is to register the core courses which offered in current semester, Fall 2018.

The Result Analysis Considered That For Courses With More Than 60 Students A Gta Should Be Hired. In Table 1 Four Classes Meet This Criterion With Four Courses. 
Table 1. Simulation Output

\begin{tabular}{c|c|c}
\hline Course & Student (Double) & Student (Integer) \\
\hline EM 5117 & 31.7 & 32 \\
EM 5140 & 97.9 & $\mathbf{9 8}$ \\
EM 5251 & 20.3 & 21 \\
EM 5255 & 15 & 15 \\
EM 5356 & 16.9 & 17 \\
EM 6182 & 92 & $\mathbf{9 2}$ \\
EM 6215 & 16.5 & 17 \\
EM 6279C & 34.1 & 35 \\
EM 6336 & 40.1 & 41 \\
EM 6357 & 31.5 & 32 \\
EM6645 & 6.9 & 7 \\
EM 6649 & 7.4 & 8 \\
EM 219 & 150.7 & $\mathbf{1 5 1}$ \\
IE 5531 & 58.5 & 59 \\
IE 6217 & 14 & 14 \\
IE 6225 & 46 & 46 \\
IE 6247 & 38 & 38 \\
IE 6532 & 15.2 & 16 \\
IS 6916 & 16.4 & 17 \\
EM 5108 & 89.5 & $\mathbf{9 0}$ \\
EM 6459 & 7.2 & 8 \\
EM 6936 & 2.6 & 3 \\
IE 6358 & 11 & 11 \\
IE 6551 & 10.6 & 11 \\
\hline
\end{tabular}

Table 2. Courses and Faculty Matrix

\begin{tabular}{|c|c|c|c|c|c|c|c|c|c|c|c|c|c|c|c|c|c|c|c|c|c|c|c|c|c|c|c|c|}
\hline & & & & $\sim$ & - & $\sim$ & - & -7 & -7 & $\sim$ & - & - & - & $-m$ & -7 & -1 & -7 & -7 & $-x$ & -7 & -1 & -7 & & & & $-m$ & -7 & \\
\hline$s=10 x+1=4$ & $\cong$ & $m$ & ‡ & & & & & & & & & & & $=$ & & & & & & & & & & & & & & 一 \\
\hline$s=40 x-4=4$, & $\cong$ & $\rightarrow$ & き & & & & & & & & & & & & & & & & & & & & & & & & & 0 \\
\hline 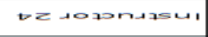 & $s$ & 一 & ₹ & & & & & & & & & & & & & & & & & & & & & & & & & - \\
\hline 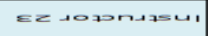 & $=$ & $\sim$ & $\approx$ & & & & & & & & & & & & & & & & & & & & & & & & & - \\
\hline ו & $\cong$ & $m$ & $\exists$ & & & & & & & & & & & & & & & & & & & & & & & $=$ & & - \\
\hline I 2 ב & $s$ & $m$ & $\nexists$ & & & & & & & & & & & & & & & & & & & & & & & & $=$ & 一 \\
\hline 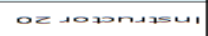 & $=$ & $m$ & ३ & & $=$ & & & & & & & & & & & & & & & & & & & & & & & - \\
\hline 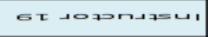 & $\cong$ & 一 & 쿨 & & & & & & & & & & & & & & & & $=$ & & & & & & & $=$ & & $\sim$ \\
\hline 8x & $E$ & $m$ & क्ष & & & & & & & & & & & & & & & & $=$ & & & & $=$ & & & & & $\sim$ \\
\hline$\angle x$ toponisu, & $E$ & 一 & $\bar{\nabla}$ & & & & & & & & & & & & & & $=$ & & $=$ & & & & & & & & & $\sim$ \\
\hline 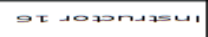 & $E$ & 一 & $=9$ & & & & & & & & & & & & & & & & & & & & & & & & & - \\
\hline 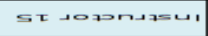 & $E$ & $\sim$ & $\exists$ & & & & & & & & & & & & & & & & & & & & & & $=$ & & & - \\
\hline De & $E$ & m & $\bar{z}$ & & & & & & & & & & & & & & & & & & & & & & & & & - \\
\hline$=x+000+x=4$, & $E$ & $m$ & $\mp$ & $=$ & & & & & & & & & & & & & & & & & & & & & & & & - \\
\hline Zx & $E$ & $m$ & ₹ & & & & & $=$ & & & & & & $=$ & & $=$ & & & & & & & & & & & & m \\
\hline I & $E$ & $m$ & $\exists$ & & & & & & & & & & $=$ & & & & & & $=$ & & & & & & & & & $\sim$ \\
\hline 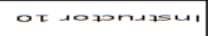 & $E$ & $m$ & 일 & & & & & & & & & & & & & & & & & & $=$ & & & $=$ & & & & $\sim$ \\
\hline 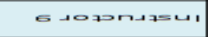 & $E$ & $m$ & $\approx$ & & & & & & & & & $=$ & & & & & & & & & & & & & & & & - \\
\hline \& & $E$ & $m$ & $\approx$ & & & & & & $=$ & & $=$ & & & & & & & & & & & & & & & & & $\sim$ \\
\hline 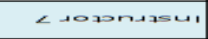 & $E$ & $m$ & $=$ & & & $=$ & & & & $=$ & & & & $=$ & & & & $=$ & & & & & & & & $=$ & & m \\
\hline 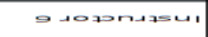 & $E$ & $m$ & $\approx$ & & & & & & & & & & & & & & & & & & & & & & & & & - \\
\hline 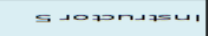 & $E$ & - & $=$ & $=$ & & & & & & & & & & & $=$ & & & & & & & & & & & & & $\sim$ \\
\hline 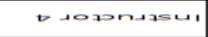 & $E$ & $\sim$ & $\neq$ & & & & & & & & & & & & & & & & & $=$ & & & & & & & & - \\
\hline$=1010 n+154$ & $E$ & $m$ & $\approx$ & & & & & & & & & & & & & & & & & & & $=$ & & & & & & - \\
\hline < & $E$ & $\sim$ & $\approx$ & & & & $=$ & & & & & & & & & & & & & & & & & & & & & - \\
\hline I & $E$ & $\sim$ & $=$ & & & $=$ & & & & $=$ & & & & & & & & & & & & & & & & & & $\sim$ \\
\hline & & 匐 & & 塄 & 气 & 쿨 & : & 萿 & 窝 & 졍 & \begin{tabular}{|l|l|l|l|l}
3 \\
\end{tabular} & है & 営 & 宽 & 量 & 害 & 害 & 蓉 & 炡 & 窝 & 로 & 寻 & 홍 & 웅 & 궁 & 菑 & 容 & 要 \\
\hline & & 磊 & & $\overline{\bar{w}}$ & $\overline{\mathrm{s}}$ & $\bar{\omega}$ & $\overline{\mathrm{s}}$ & $\bar{\omega}$ & $\overline{\mathrm{s}}$ & $\overline{\mathrm{s}}$ & $\overline{\mathbf{z}}$ & $\overline{\mathbf{s}}$ & $\bar{\sigma}$ & $\bar{\omega}$ & $\overline{\bar{w}}$ & $\overline{|s|}$ & $\overline{\mathrm{s}}$ & $\bar{\omega}$ & $=$ & $=$ & $=$ & $=$ & $=$ & $=$ & $=$ & $=$ & $=1$ & 훙 \\
\hline & & & & $=$ & $\approx$ & $=$ & $\Rightarrow$ & 5 & & & & & & & & & & & & & & 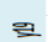 & 3 & 部 & 政 & $\approx$ & 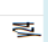 & \\
\hline
\end{tabular}




\section{CONCLUSION SUGGESTIONS \\ 4.1. Conclusion}

A financial model is proposed in this paper for IE department in a major University in the Middle East. An objectoriented simulation software is used to run the financial model. The model ran to optimize the number of courses to be taught for the current enrolled students based on the availability of instructors in each track. However, based on the information for full time and part time faculty, there are more resources available than available courses, thus a linear programming did not work. (In the Fall of 2018 number of course that taught is 24 , and there is a maximum teaching availability of 61 courses. See Table 2 for more information.) The study also shows number of courses with more than 60 students that a GTA (Graduate Teaching Assistant) should be hired. Likewise, it shows the optimum number of courses to be taught based on the availability of instructors in each track.

\subsection{Suggestions}

Future works might include to run the simulation for the different departments in the college, run the simulation by applying to different colleges, such as Education, Business Administration, etc. Also, further financial analysis can be conducted.

\section{REFERENCES}

Bookstaber, R., Paddrik, M., \& Tivnan, B. (2018). An agent-based model for financial vulnerability. Journal of economic interaction and coordination, Vol.13, No.2, 433-466.

Chapman, B., \& Doris, A. (2018). Modelling higher education financing reform for ireland. Economics of education review. Article in press.
Elias, H., \& Mehrotra, A. (2018). Activitybased costing of library services in universities-a case study of a private university. Economics world, Vol.6, No.3, 165-176.

Folsom, R. B. (2019). How to get grant money in the humanities and social sciences. Yale university press. Retrieved from https://yalebooks.yale.edu/book/9780 300217438/how-get-grant-moneyhumanities-and-social-sciences.

Gustafsson, R., \& Jarvenpaa, S. (2018). Extending community management to industry-university-government organizations. $R \& D$ management, Vol.48, No.1, 121-135.

Harmon, P., \& Watson, M. (1998). Understanding UML: the developer's guide: with a web-based application in java. Retrieved from https://books.google.com/books?hl=e $n \& l r=\& i d=9 q 8$ utojjj $1 q c \&$ oi $=$ fnd $\& p g$ $=$ pal $\& d q=$ understanding $+u m l:+$ the + developer's + guide: + with $+a+$ webbased + application $+i n+j a v a \& o t s=k j$ $4 r 4 \_1 u v-\&$ sig $=-$ dgfvi4p4nfpf_ffypur4mOfqzo.

Johnes, J. (2015). Operational research in education. European journal of operational research, Vol.243, No.3, 683-696.

Kumar, L., Jindal, A., \& Velaga, N. R. (2018). Financial risk assessment and modelling of ppp based indian highway infrastructure projects. Transport policy, Vol.62, 2-11.

Mardiansyah, R. F., Kusrini, E., \& Rm, F. (2018). Analisa ekonomis peralatan pulverizer untuk optimalisasi keandalan pltu dengan simulasi monte carlo dan pendekatan analisa biaya siklus hidup (studi kasus: pltu x). Jurnal teknoin, Vol.23, No.3, 275288. 
Reardon, S. F., Baker, R., Kasman, M., Klasik, D., \& Townsend, J. B. (2018). What levels of racial diversity can be achieved with socioeconomic-based affirmative action? evidence from a simulation model. Journal of policy analysis and management, Vol.37, No.3, 630-657.

Roques, P. (2006). UML in practice: the art of modeling software systems demonstrated through worked examples and solutions. Retrieved from

https://books.google.com/books?hl=e $n \& l r=\& i d=n q g v z s-$

$y$ sycc \&oi $=$ fnd $\& p g=p r 7 \& d q=u m l+i n$ + practice: + the + art + of + modeling $+s$ oftware + systems + demonstrated + thr ough+worked + examples + and + soluti ons\&ots $=z-$

hsehvpev\&sig=0csqfhigrnu5bvhgijvp uubydvq.

Steffen, B. (2018). The importance of project finance for renewable energy projects. Energy economics, Vol.69, 280-294.

Strang, K. D. (2012). Applied financial nonlinear programming models for decision making. International journal of applied decision sciences, Vol.5, No.4, 370-395.

Toklu, S., \& Simşek, M. (2018). Two-layer approach for mixed high-rate and low-rate distributed denial of service (ddos) attack detection and filtering. Arabian journal for science and engineering, Vol.43, No.12, 79237931. 